\title{
THE GRAMMATICAL CONTROVERSY OF SHEIKH ABDUL RAHMAN BIN MUHAMMAD, KNOWN AS AL-
} NARI

Istanbul / Türkiye

\section{p. $51-61$}

\section{Article Information}

Article Type: Research Article This article was checked by iThenticate No plagiarism detected

\section{Article History}

Received: 06/08/2021

Accepted: $21 / 08 / 2021$

published: $01 / 09 / 2021$

\begin{abstract}
:
Disagreement occurred between the Basri and Kufi doctrines, in many branches, and each of them went to support his doctrine according to the method that he followed with textual and rational evidence, and the difference increased and raged between them for a long time, and the early scholars alerted to this grammatical dispute, and the first to write about it was a fox ( D. $291 \mathrm{AH}$ ) wrote his book (The Difference of Grammarians), then after that synonymous and successive writings, and from here, my research was called (The Grammatical Principles of AlAari in his book, Moniyat Al-Ragheb and for the sake of the student), and it included three sections. The first: the controversial issues that he preferred, while the second topic included the controversial issues that the author left without weighting, and the third topic was the issues that were called the agreement between scholars and they are originally in dispute: It contains a number of Arabic sources, the most important of which are: Sibawayh's Kitab, Al Muqtada, Al Osoul in Grammar, Sharh Al Mufassal, Rashrif Al-Baqarah, and other sources.
\end{abstract}

Key words: Grammatical Disagreement, Aleari, Arabic Grammar, Text Verification.

http://dx.doi.org/10.47832/2791-9323.3-2.5

Dr. , Iraqi University, Iraq, almshaykhya13@ @mail.com, https://orcid.org/0000-0001-9562-8105

2 (iD) Researcher, Iraqi University, Iraq, ahmadhamed19980@ gmail.com, https://orcid.org/0000-0003-4292-2495

Copyright ๑ Published by IJEl Journal, www.ijeljournal.com Rimar Academy, Fatih, Istanbul, 34093 Turkey All rights reserved 


\title{
الخلاف النحوي عند الشيخ عبد الرحمن بن محمد الشهير بالعاري
}

\author{
أحمد جاسم محمد 3 \\ أحمد حامد علي المحمدي 4
}

\begin{abstract}
الملخص

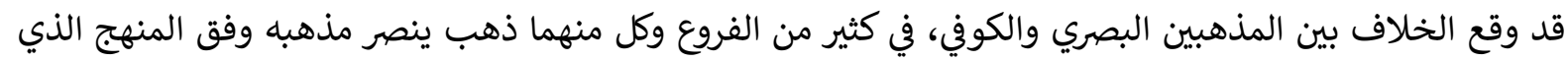

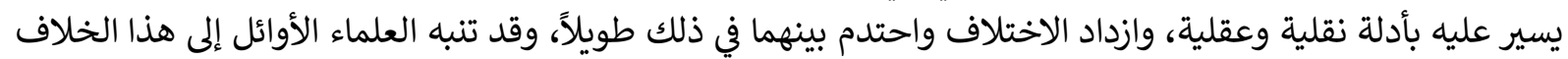

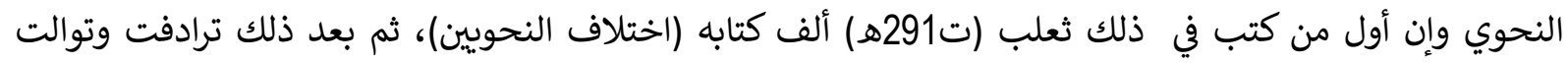

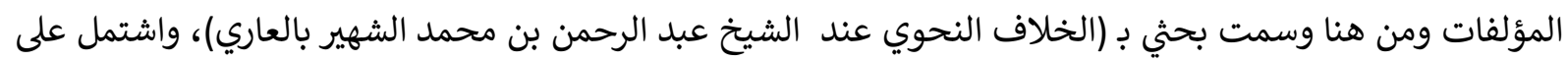

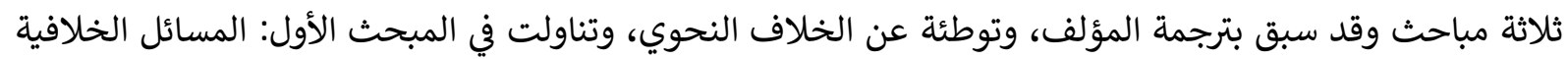

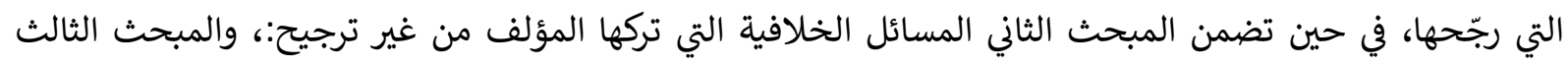

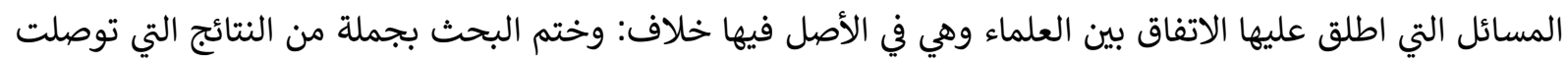

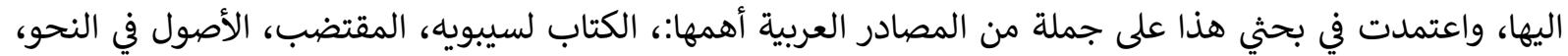

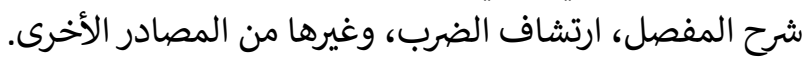
الكلمات المفتاحية: الخلاف النحوي، العاري، النحو العربي، تحقيق النهري، النصوص.
\end{abstract}

المقدمة:

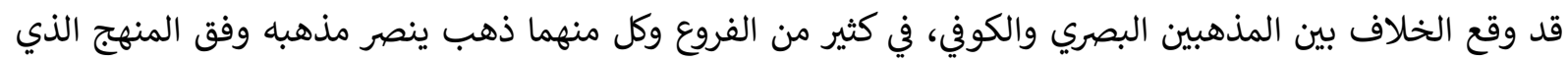

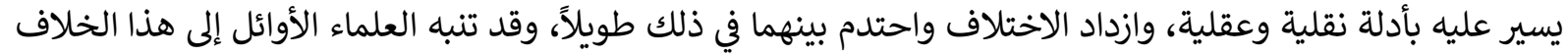

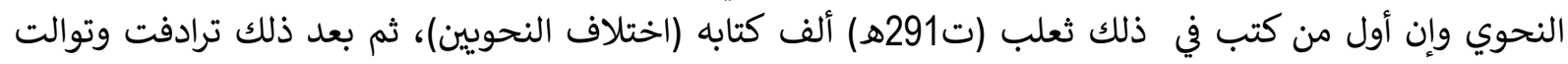

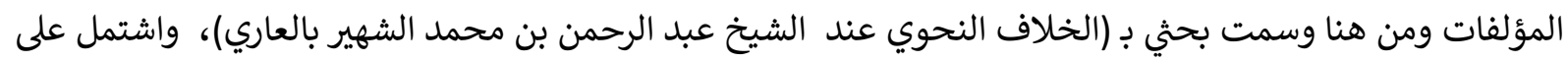

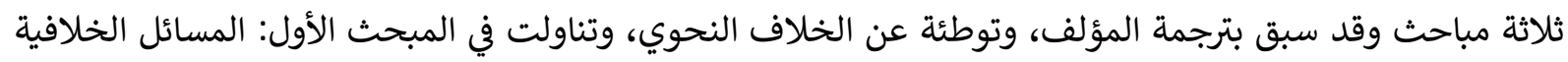

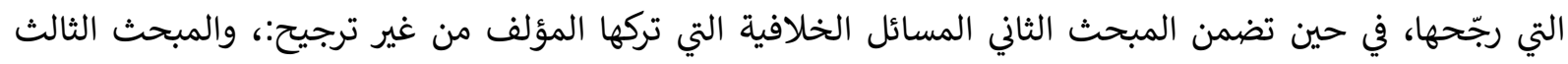

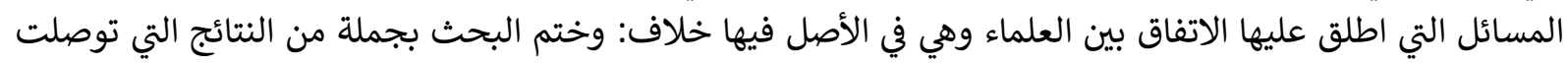

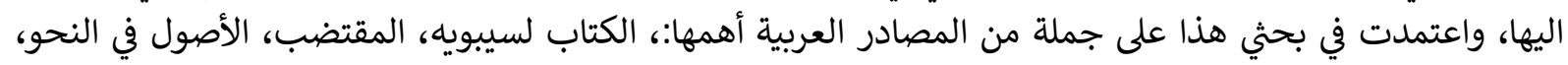

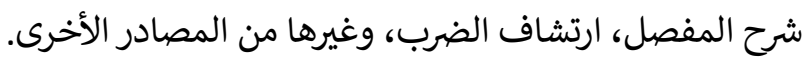

توطئة:

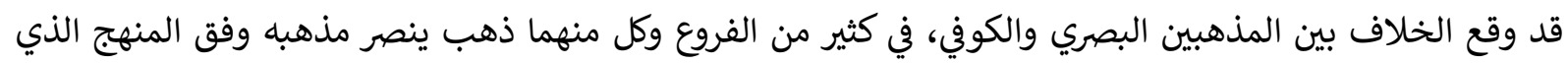

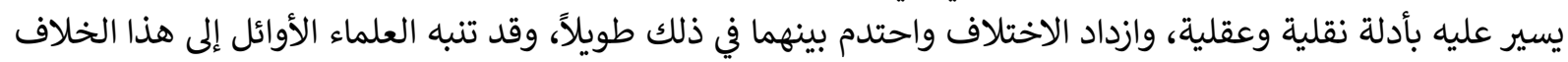

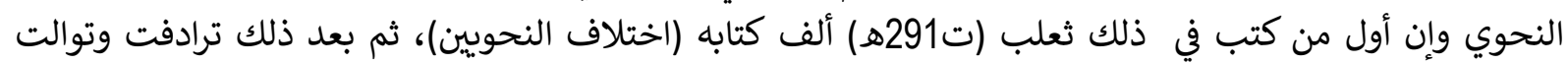

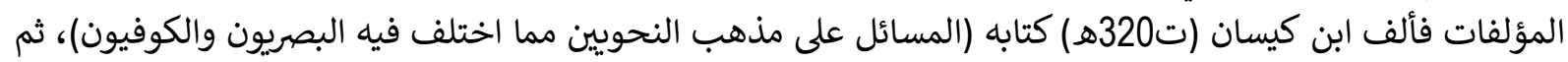

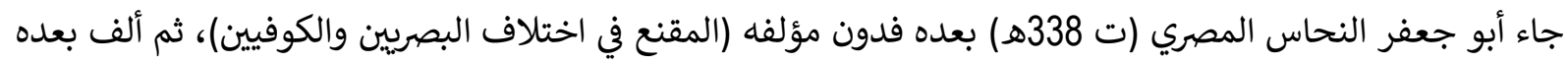

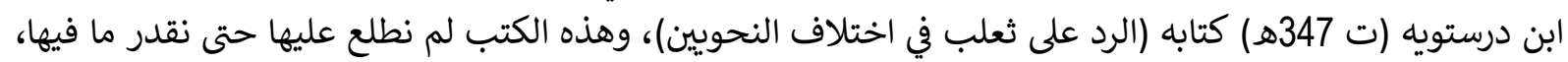

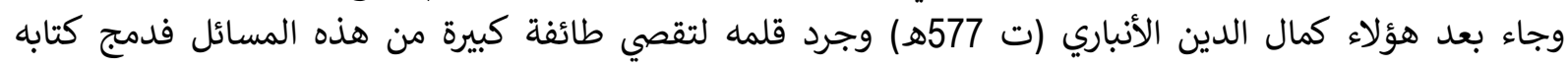

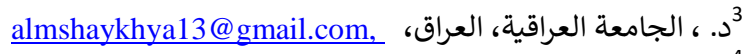
ahmadhamed19980@gmail.com الباحث، الجامعة العراقية، العراق، العاق، العراق، 
(الإنصاف في مسائل الخلاف بين النحويين: البصريين والكوفيين) وأجاد فيه أيما إجادة1، وهناك مؤلفات أخرى في

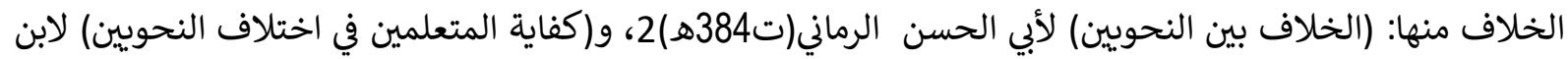
فارس(ت395هـ) وقد عبر الشيخ العاري عن الخلاف في كتابه (منية الراغب وبغية الطالب) بأقوال صريحة، واقوال أخرى تدل على معلى معناه،

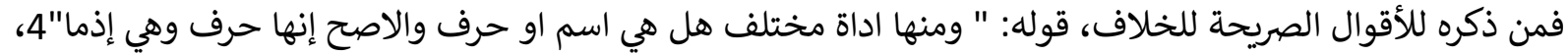

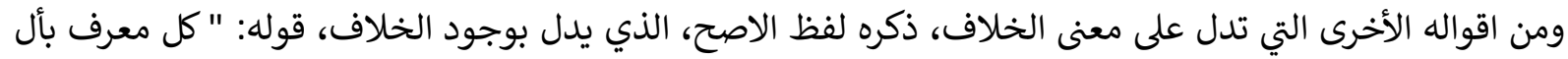

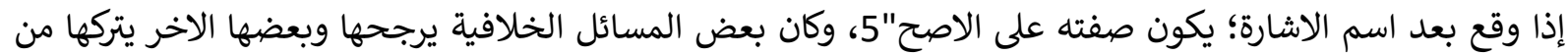

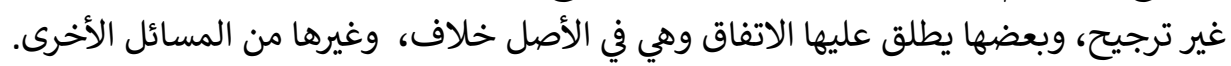

\section{المبحث الأول: المسائل الخلافية التي رجّحها: - (المها: 1. مسألة (التقدير في الكسر):}

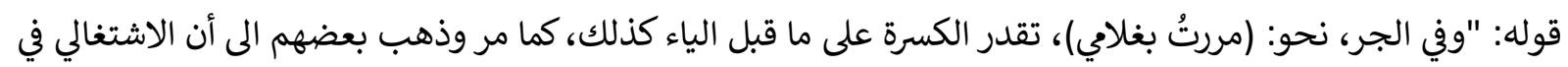

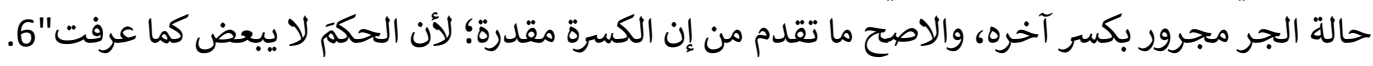

2. مسألة(كل ما ليس له مفرد من لفظه إذا ورد على هيئة جمع المذكر السالم فهو ملحق به):

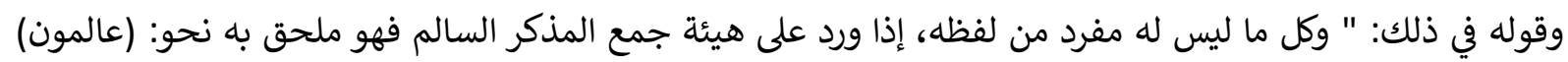

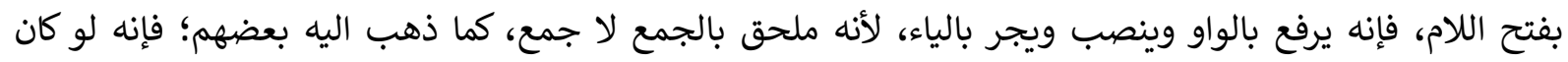

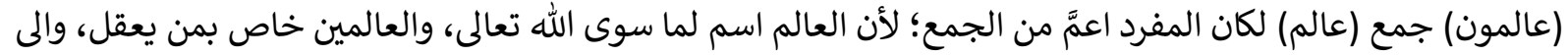

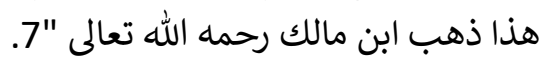

3. مسألة (المعرف بـ (أل) إذا وقع بعد اسم الإشارة):

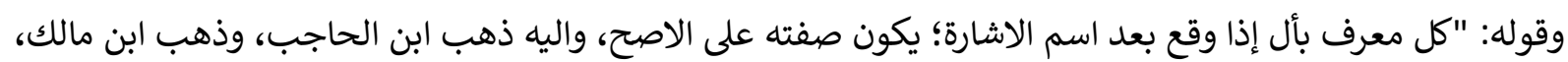

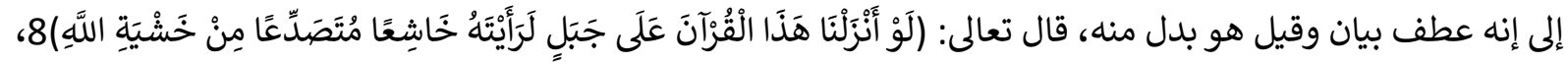

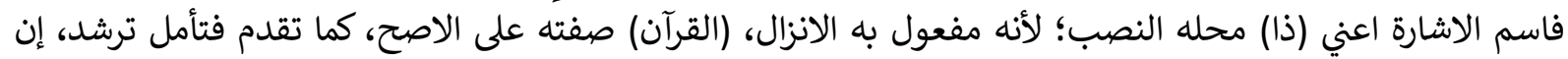

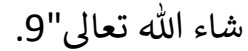

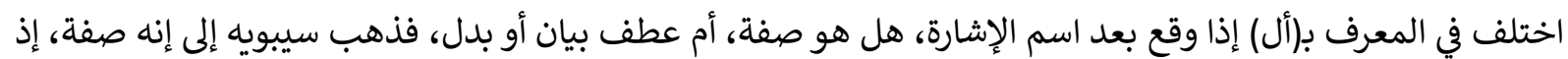

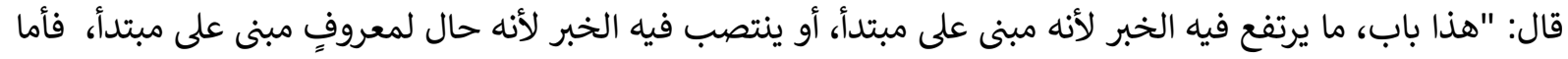

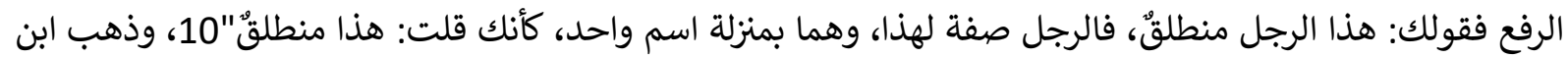

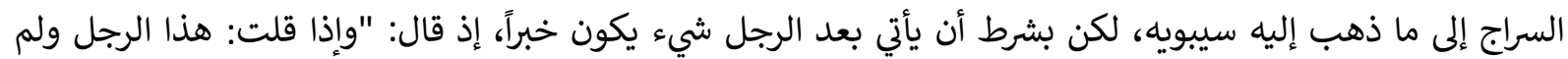

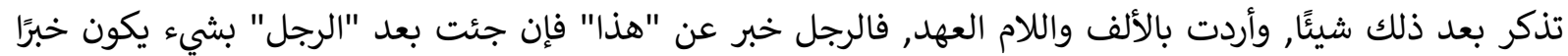

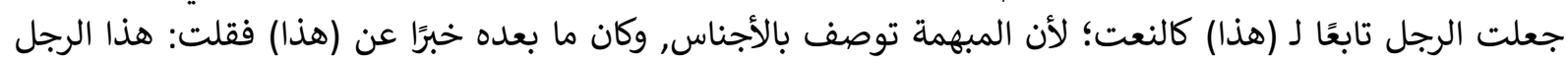

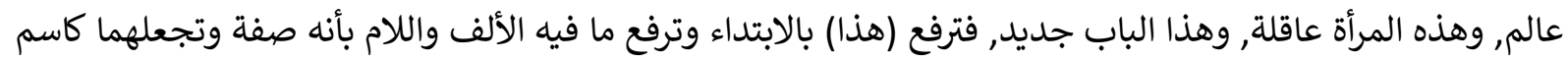

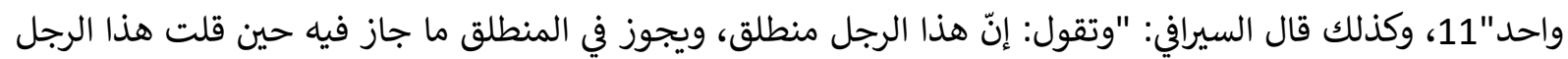

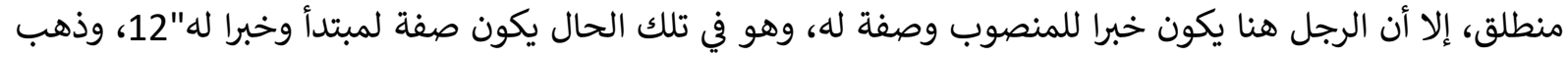

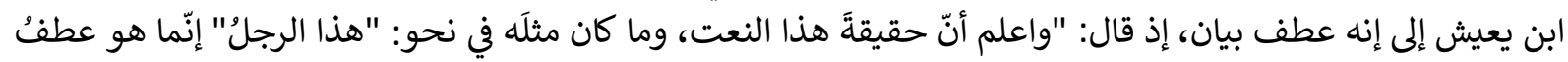

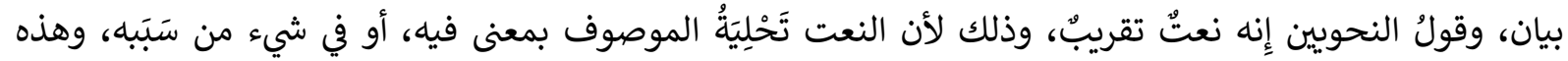

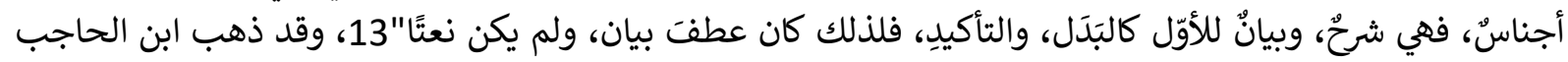
إلى ما ذهب إليه سيبويه وابن السراج. 
وقوله: "واعلم ان العطف على الضمير المرفوع المتصل من غير فأصل ضعيف نحو: (جئت وزيد) فالأصح ان يقال:

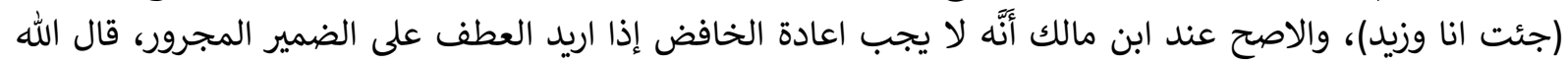

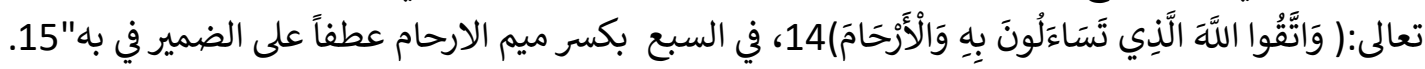

\section{5. مسألة (الاداة إذما هل هي اسم أم حرف):}

وقوله: "ما يجزم فعلين، يسمى الفعل الأول فعل الشرط، ويسمى الفعل الثاني جواب الشرط، وهو احد عشر اداة: منها

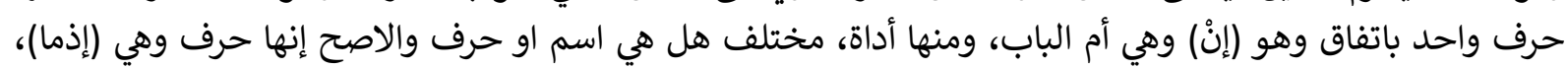

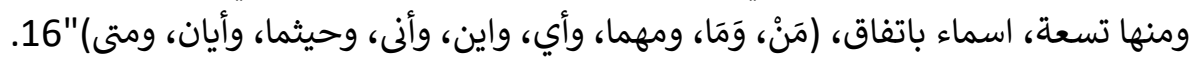

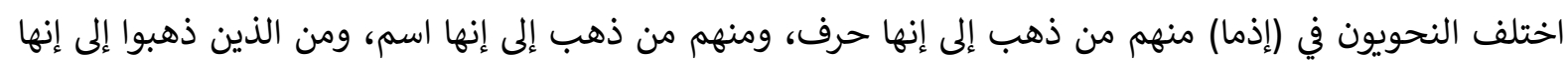

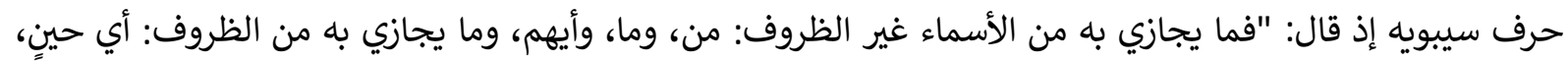

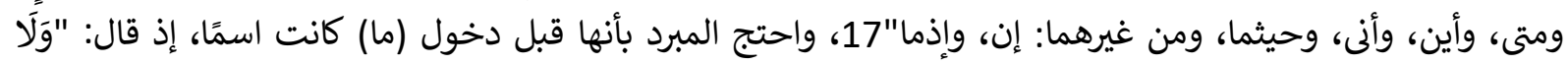

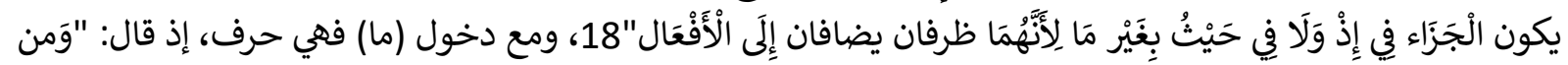

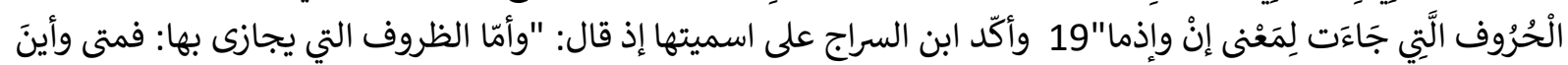

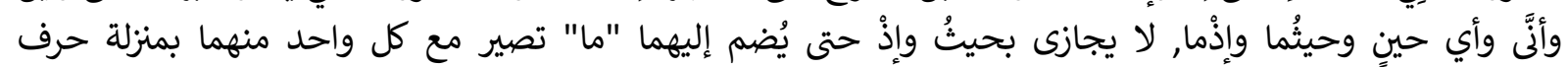

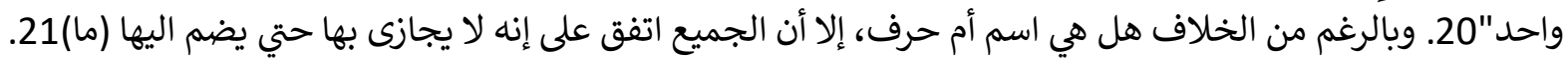

6. مسألة (رفع الاسم الظاهر باسم التفضيل):

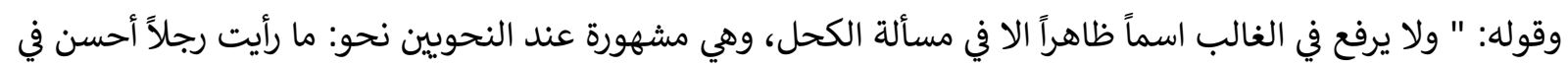

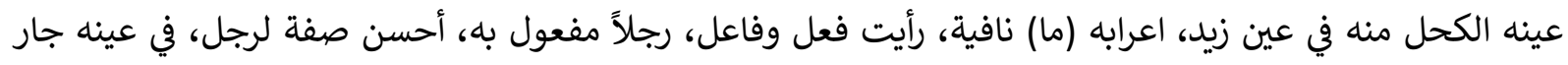

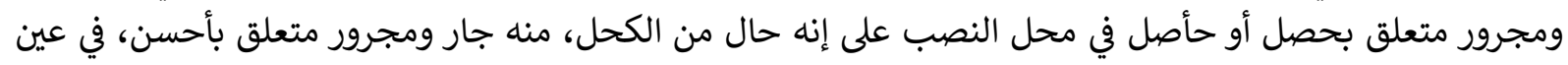

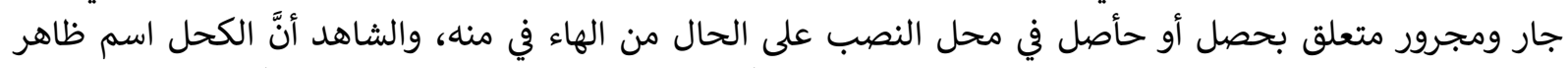

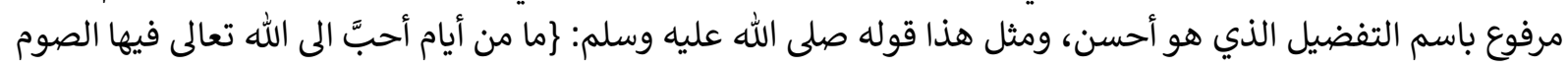

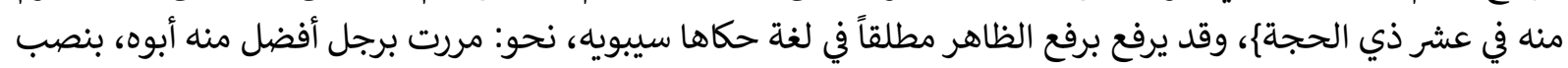

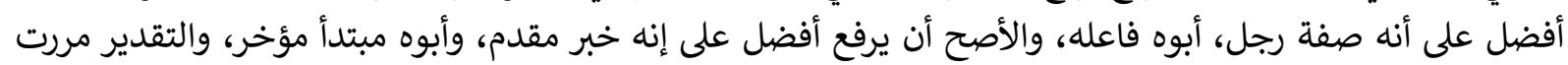
برجل أبوه أفضل منه"

المبحث الثاني: المسائل الخلافية التي تركها المؤلف من غير ترجيح:

1. مسألة الخلاف في (أل التعريف):

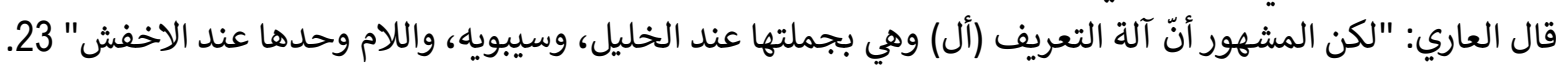

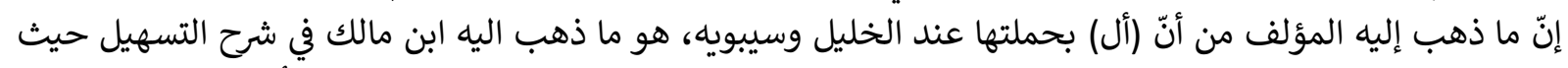

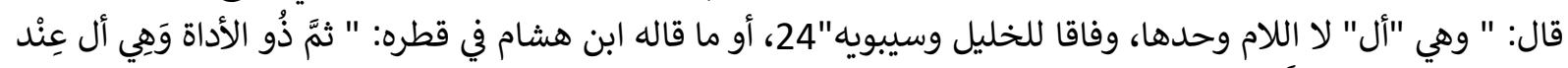

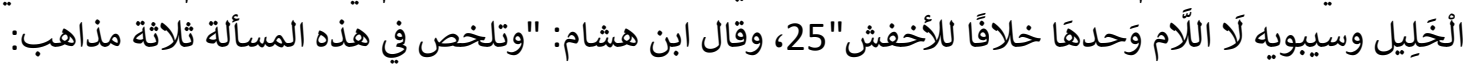

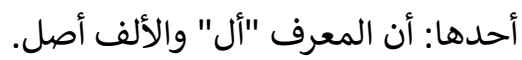

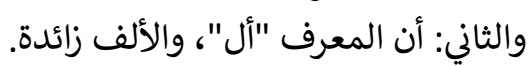

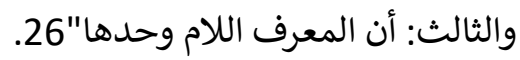
وأسقط مذهبا رابعاً: وهو أن المعرف الهمزة وحدها، والهاب اللام زائدة للفرق بينها وبين همزة الاستفهام، وهو مذهب المبرد

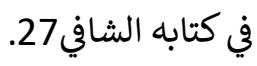


إن المعرف "أل" والألف أصل: هذا المذهب يدل على أن (أل) ثنائية الوضع ك (قد، وهل)، فهي بحملتها اداة التعريف،

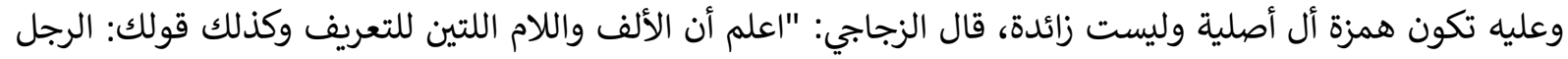

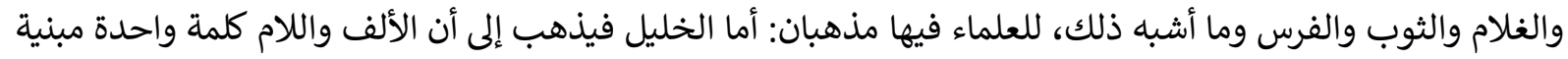

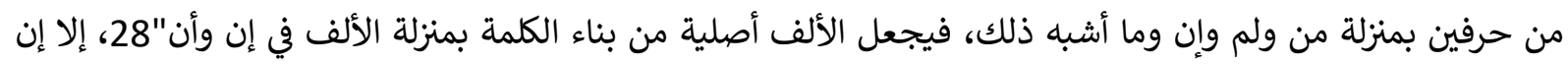

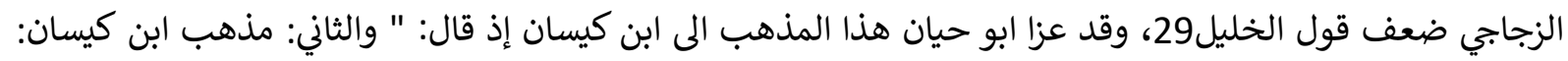

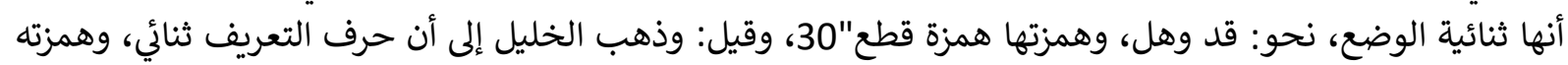

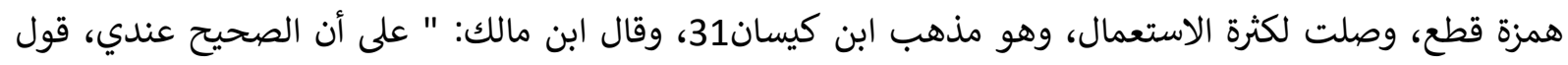

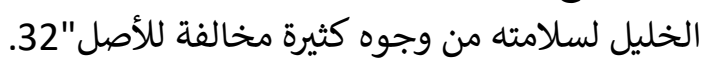

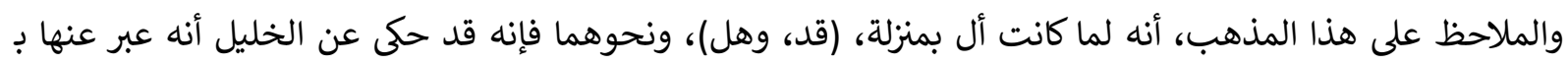

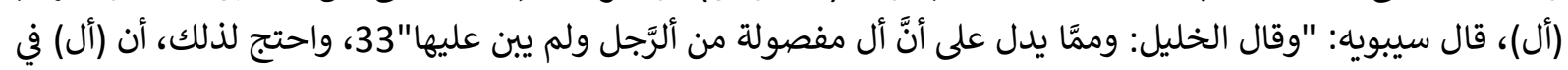

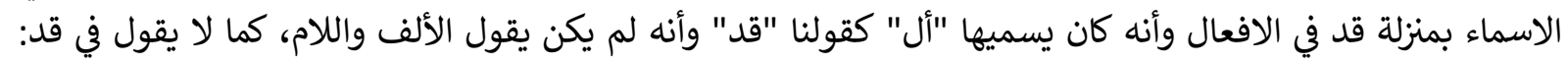

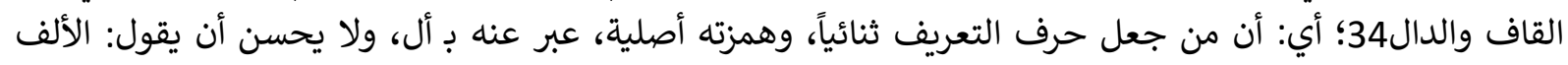

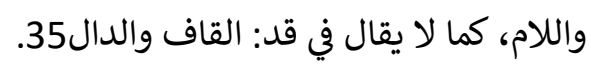

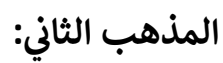

أن المعرف (أل)، والألف زائدة: أن أل بجملتها هي أداة التعريف، وهمزتها همزة وصل زائدة لثبوتها في الابتداء، وهذا ما

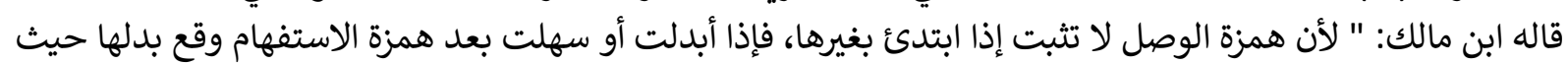

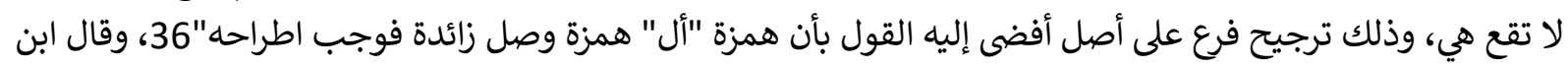

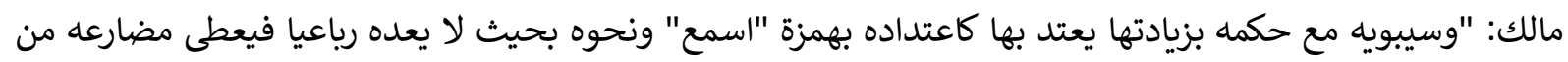

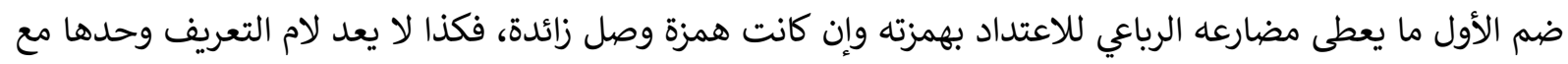

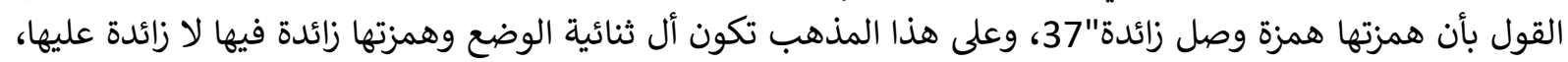

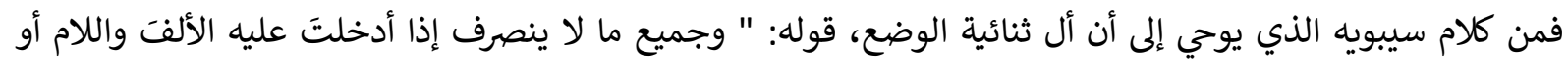

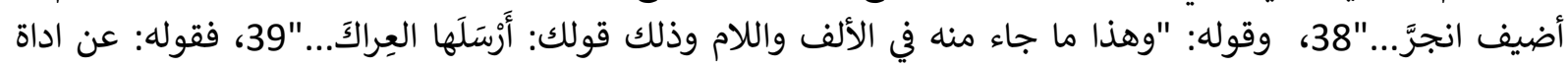

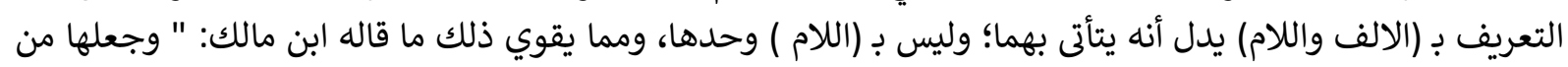

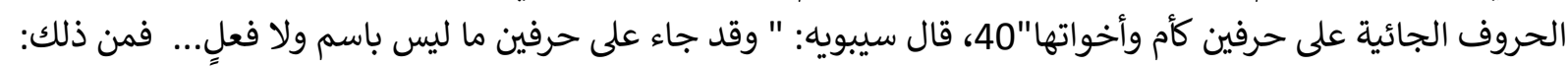

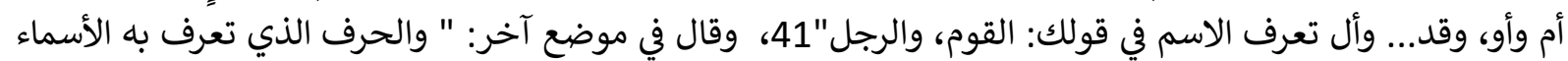

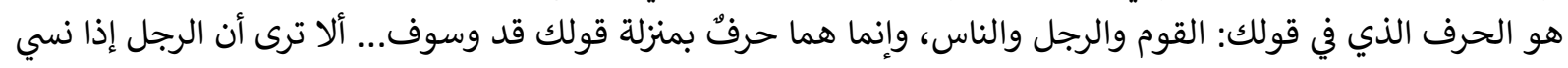

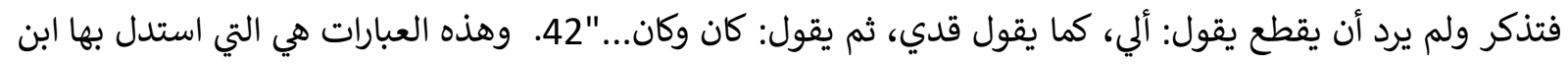

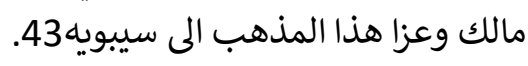

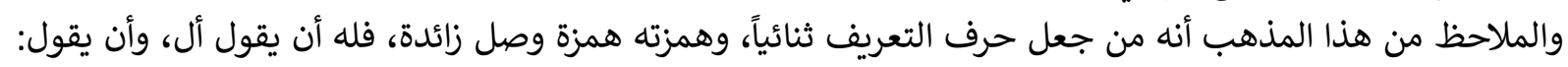

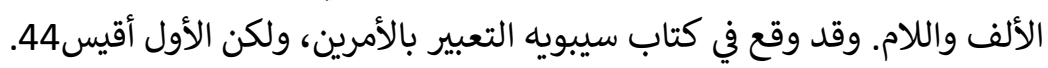

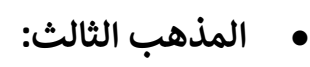

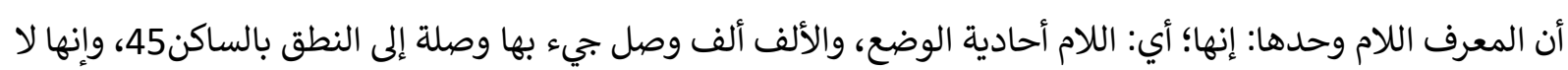

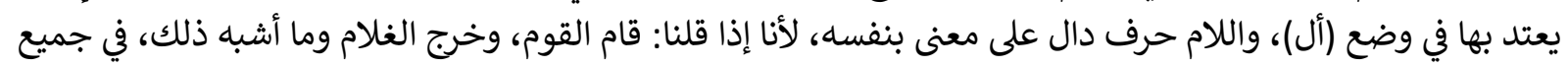

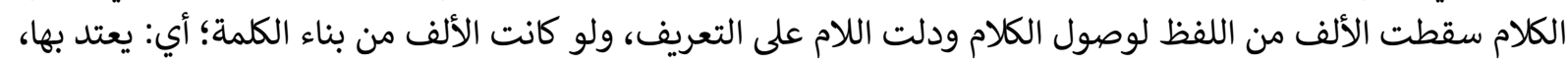

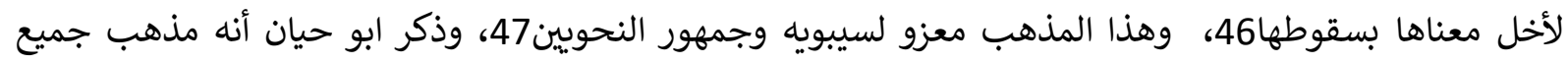

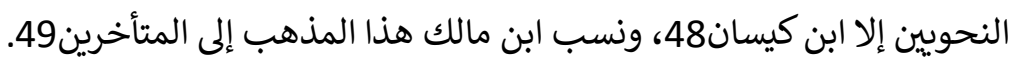




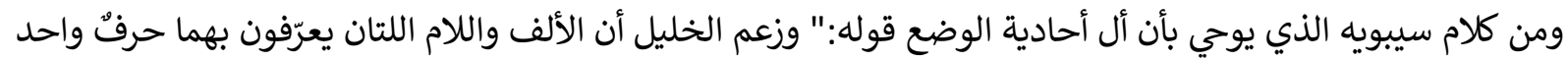

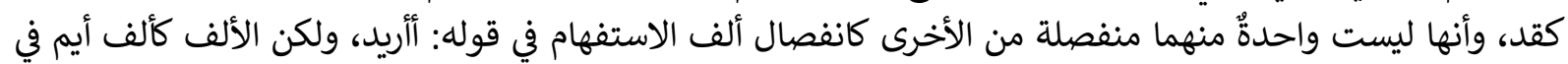

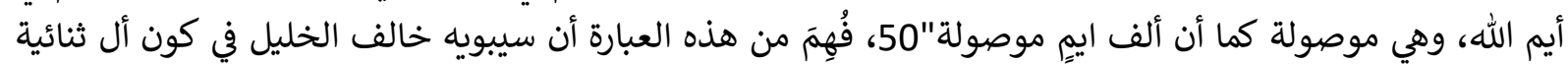

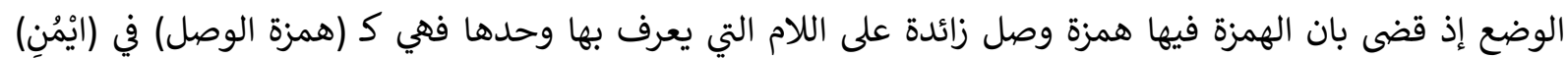

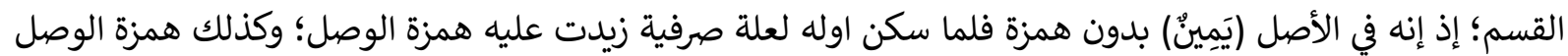

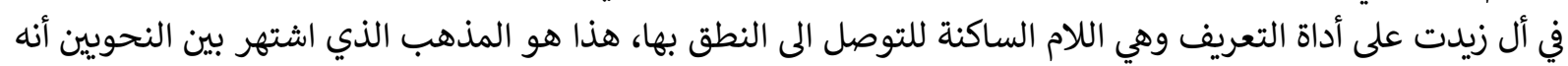

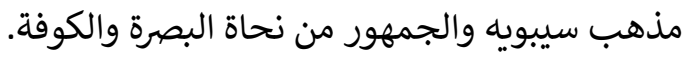

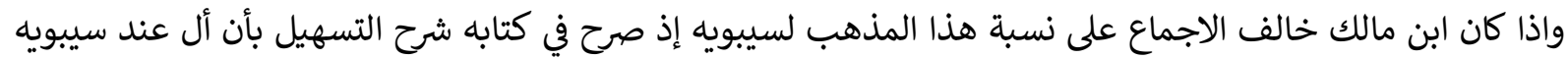

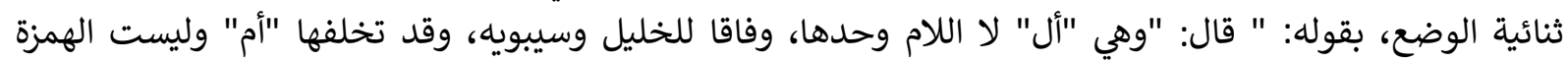

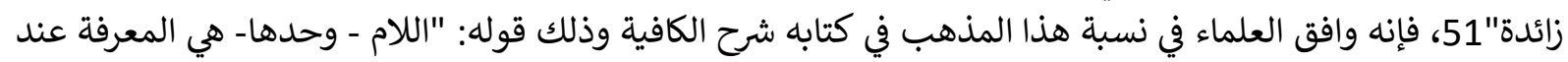

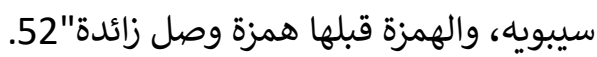

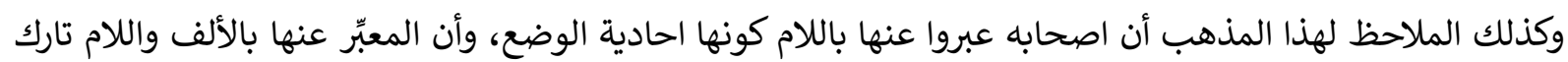
لما هو أولى، وكذا المعبر عنها بأل53.

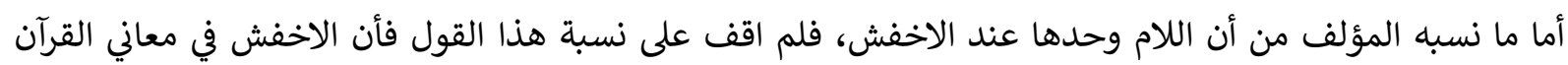

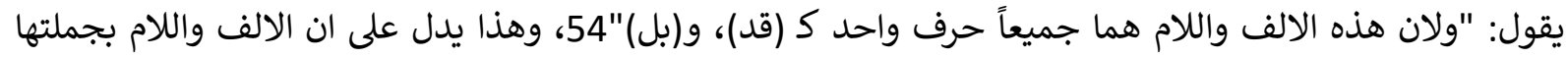

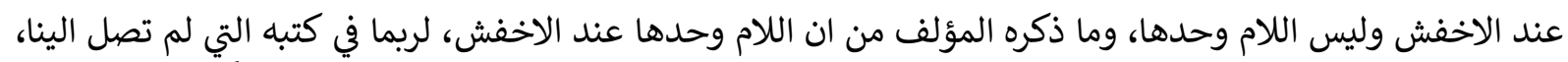

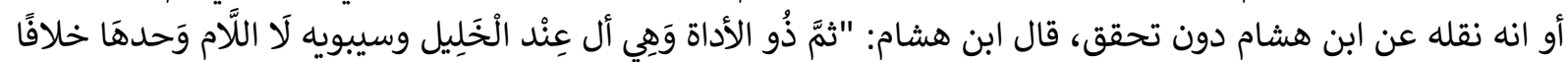

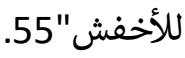

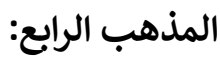

\section{أن المعرف الهمزة وحدها:}

هذا القول الرابع من الاقوال التي قيلت في ماهية (أل) المعرفة، والذي لم يتطرق اليه العاري، وهو أن المعرف الهمزة

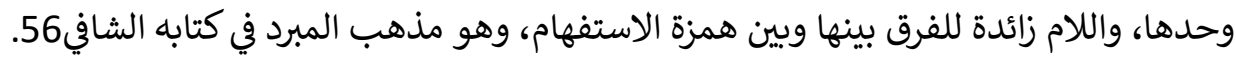

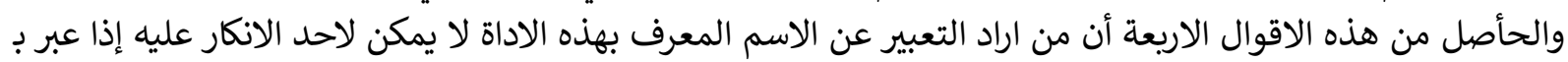

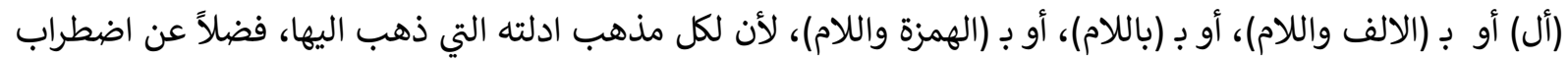

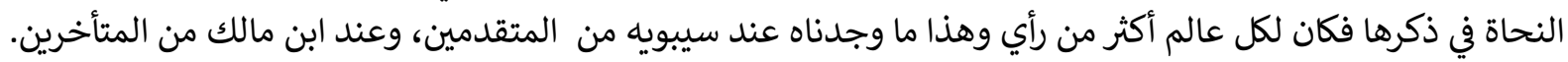

مسألة (الجمع بين الفاعل والتمييز):

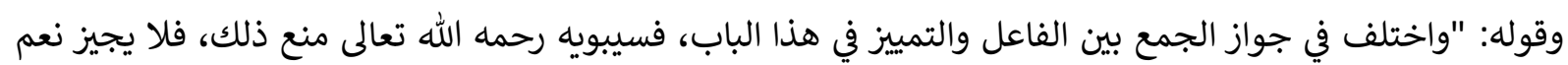

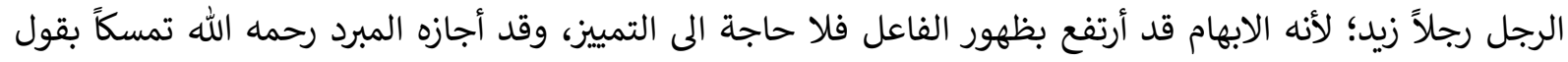

\section{فَحْحًا وَأَمُهُهُمُ زَلَّلاءُ مِنْطِيقُ}

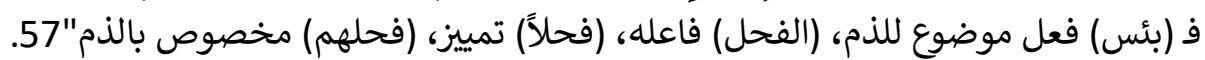

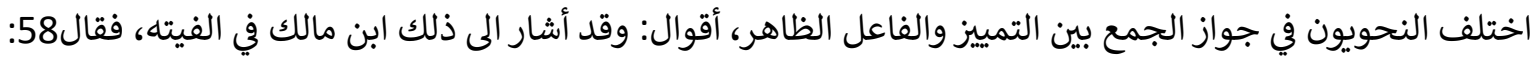

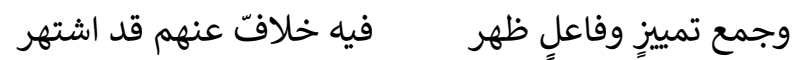

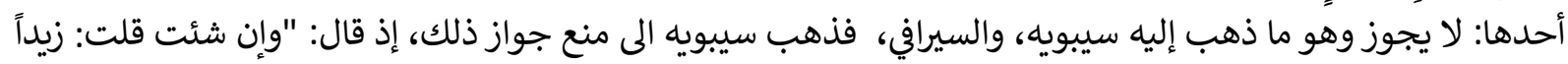

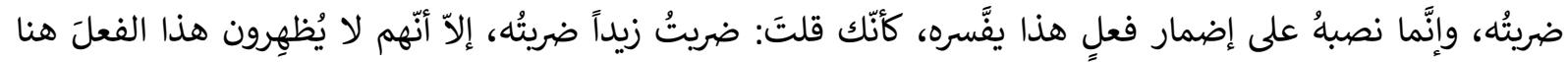

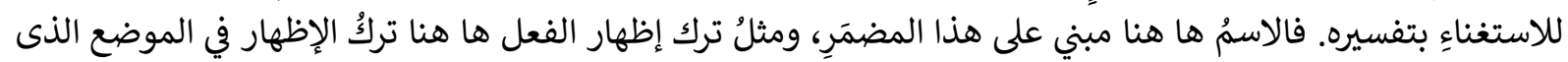

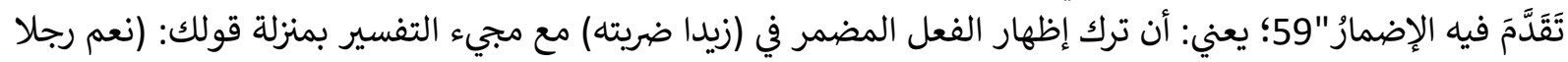


زيد) وتقديره: (نعم الرجل رجل زيد)، أضمر الرجل في (نعم)؛ لأن (نعم) فعل، ولا بد له من فاعل و (رجلا) تفسير له،

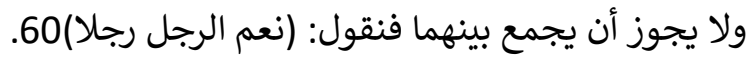

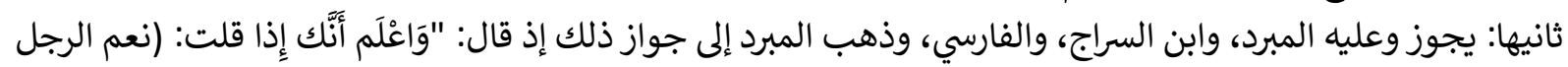

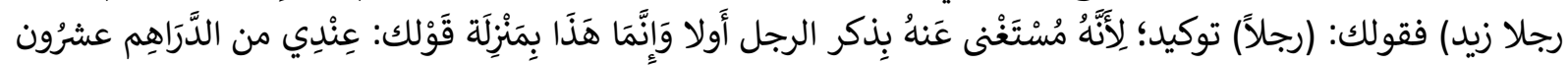

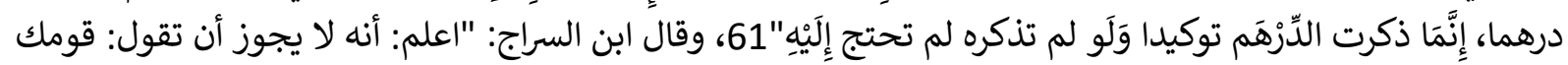

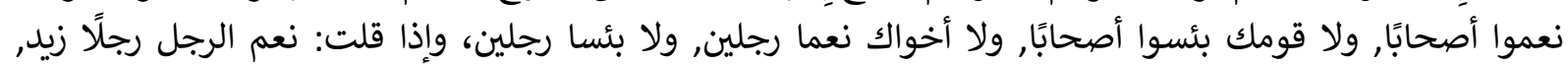

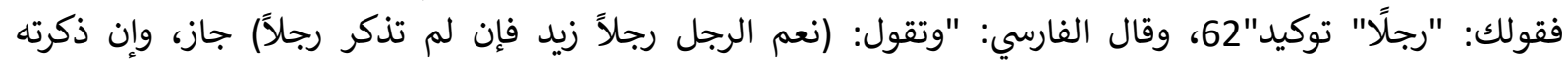
فتأكيد"63. وأختار ابن مالك هذا القدأ القول إذ قال: "ولا يمنع منه زوال الإبهام بدونه؛ لأن التمييز قد يجاء به توكيداً، كقوله عز وجل:

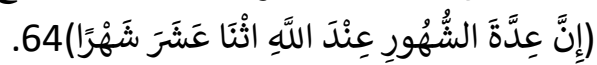

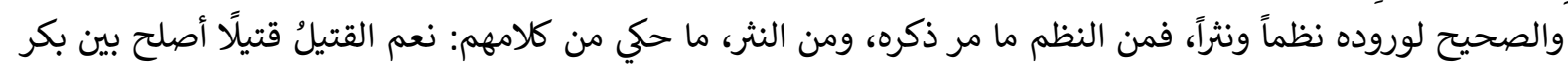

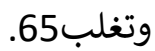
ثالثها: وفصل بعضهم فقال: إن أفاد التمييز فائدة زائدة على الفاعل جاز الجمع بينهما، نحو: نعم الرجل فارساً زيد، وإلا

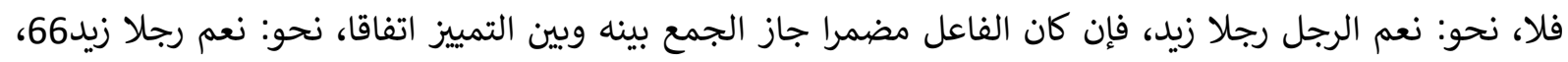

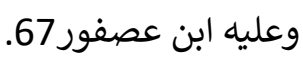

المبحث الثالث المسائل التي اطلق عليها الاتفاق بين العلماء وهي في الأصل فيها خلاف 1. مسألة (تقديم المستثنى على المستثنى منه):

قوله: "أما إذا تقدم المستثنى على المستثنى منه فيجب النصب مطلقاً؛ أي: في المنقطع وغيره نحو: ما قام الازيداً أحد،

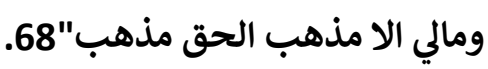

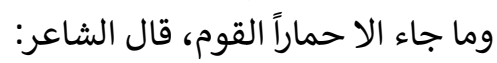

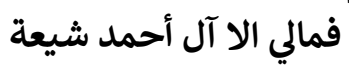

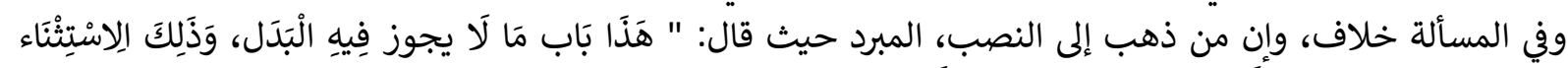

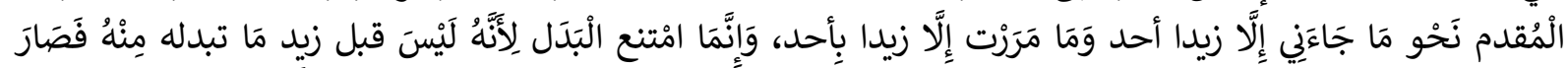

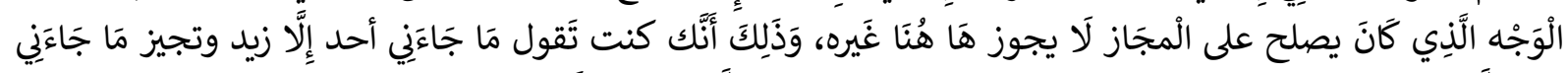

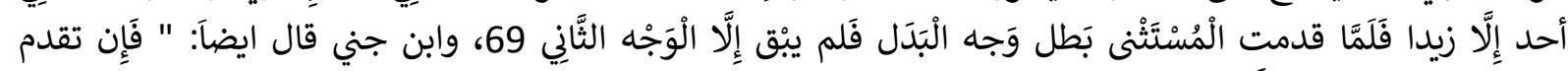

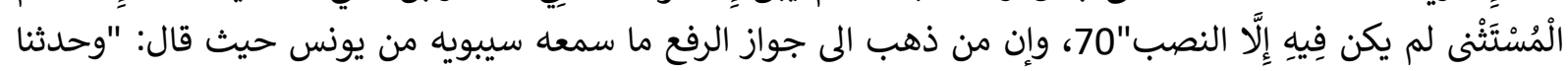

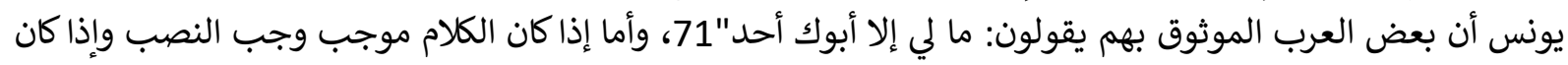

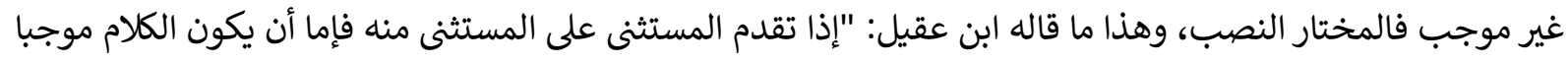

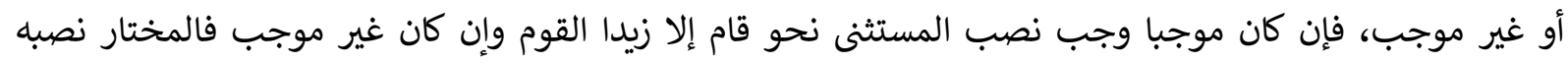

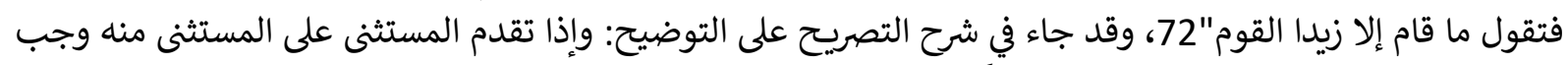

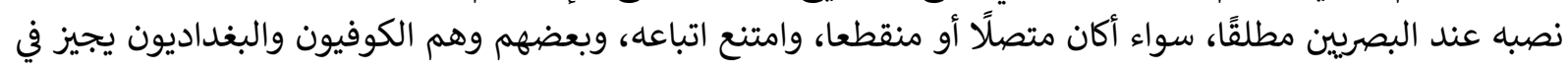

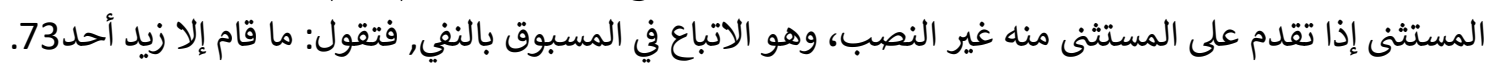

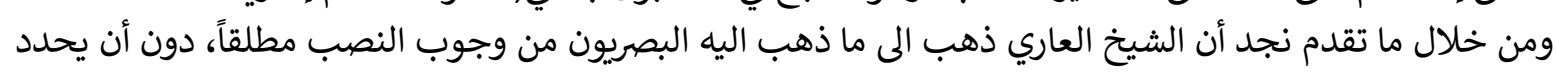
مذهب من النحاة فتركه على الاطلاق دون تقييد.

1. - مسألة (إعمال اسم المصدر): وقوله: "الثالث: من الاسماء التي تعمل عمل الفعل: اسم المصدر وهو ما ساوى المصدر في الدلالة وخالفه بخلوه عن ونكاء

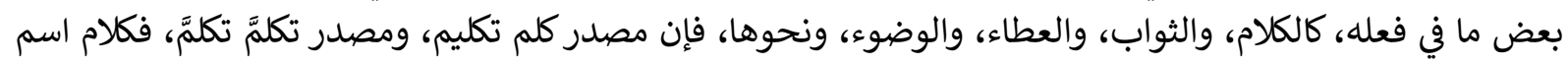

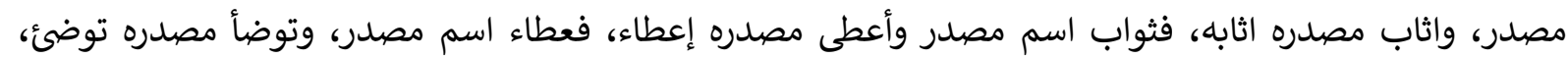

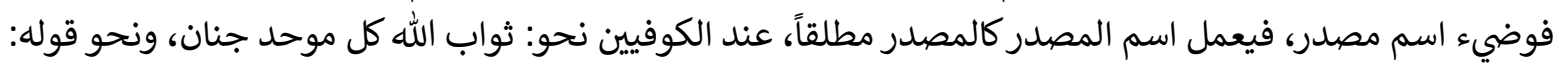




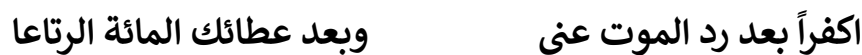

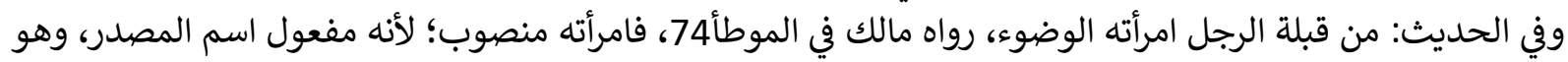

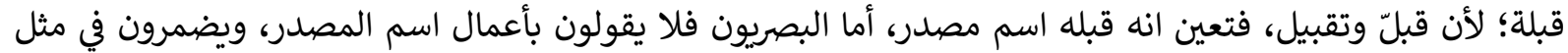

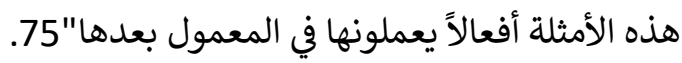

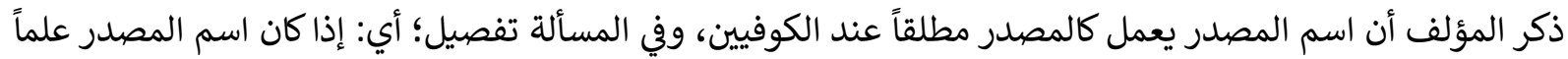

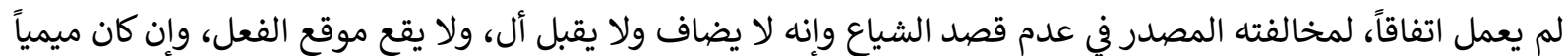

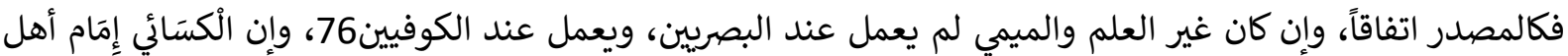

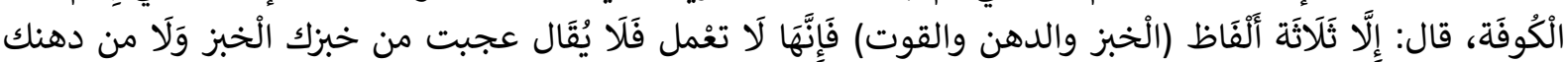

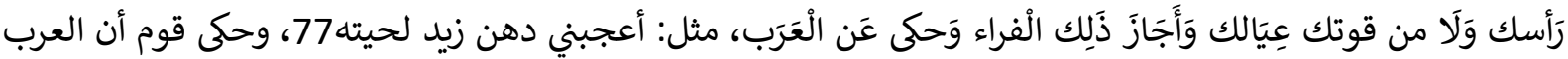
قد وضعت الأسماء في مواضع المصادر فقالوا: عجبت من طعامك طعاك طعامًا, يريدون: من إطعامك, وعجبت ديت من دهن دهنك

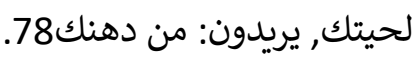

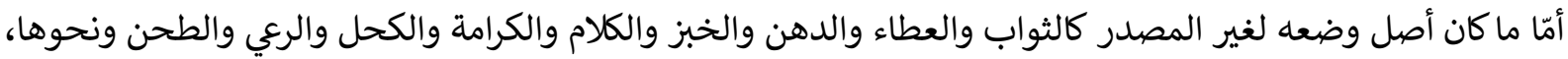

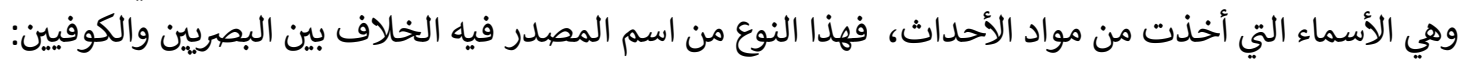

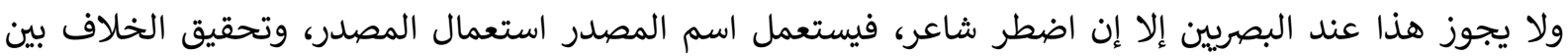

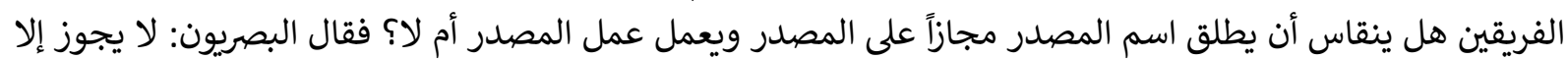

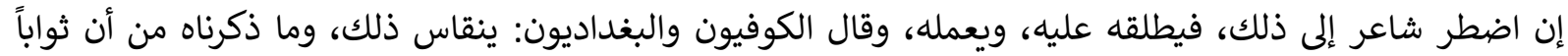

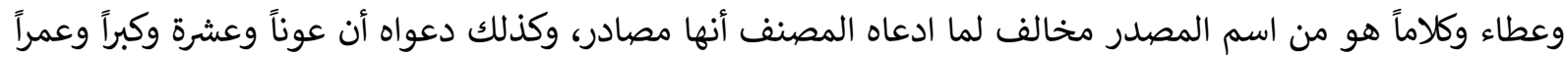

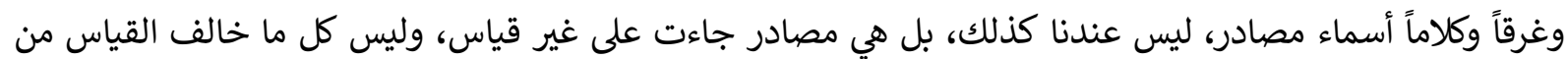

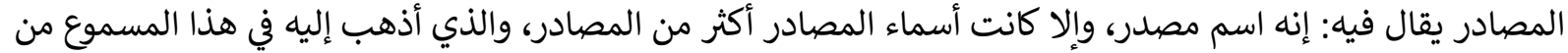

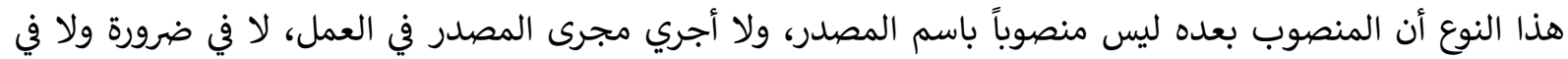

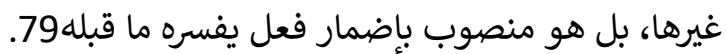

الخاتمة

الحَمْدُ للهِ الَّي يَسََّر بمنّّه وفضْله وعوْنه على إتمام هذا البحث، ومن خلال الموضوعات التي ذكرت والتي سبق الحديث عنها وصلنا إلى أهم النتائج:

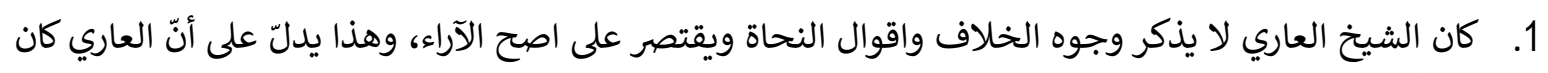

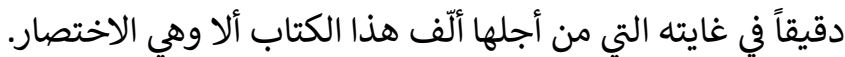

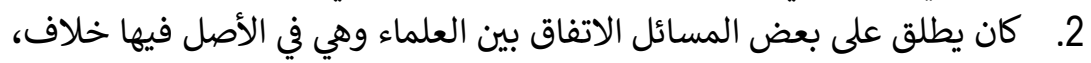

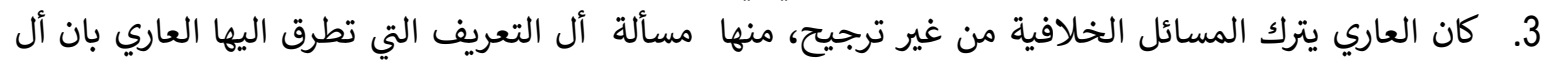

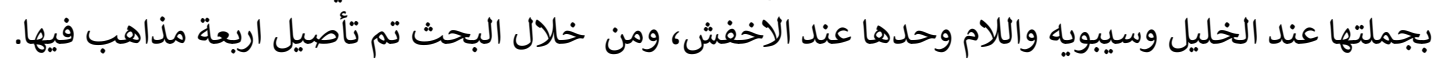


ارتشاف الضرب من لسان العرب: أبو حيان محمد بن يوسف بن علي بن يوسف بن حيان أثير الدين الأندلسي (المتوفى:

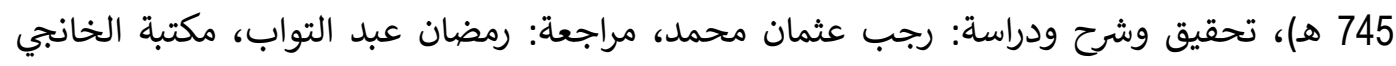
بالقاهرة، ط/ الأولى، 1418 هـ - 1445 هـ 1998 م.

الأصول في النحو: أبو بكر محمد بن السري بن سهل النحوي المعروف بابن السراج (المتوفى: 316هـ)، تح/ عبد الحسين

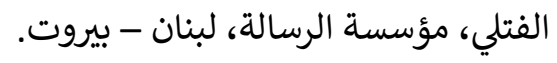

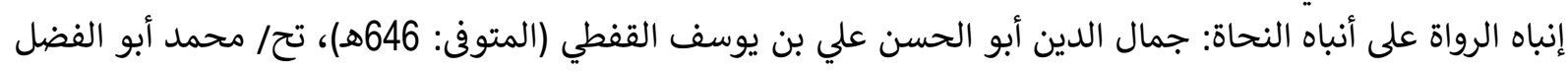

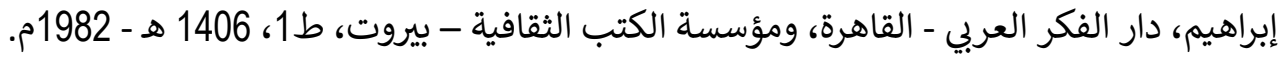

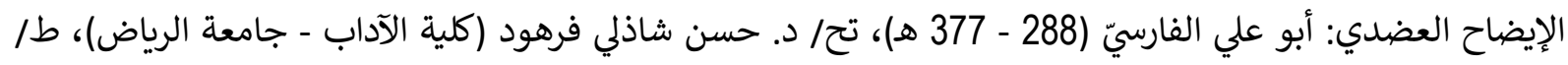

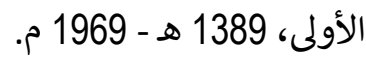

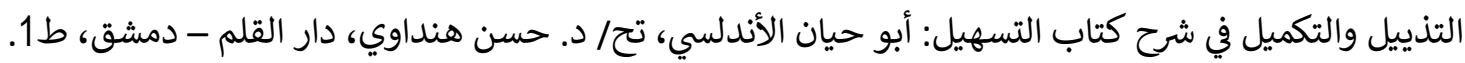

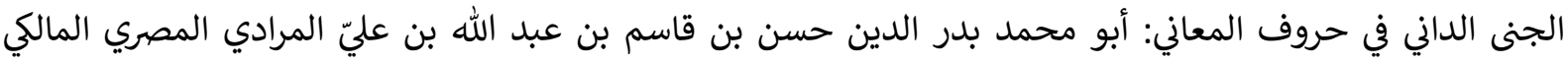

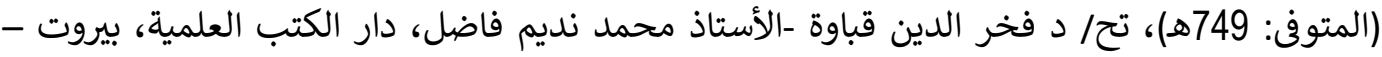

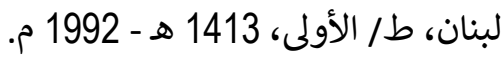

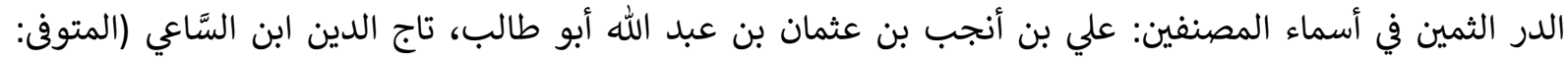

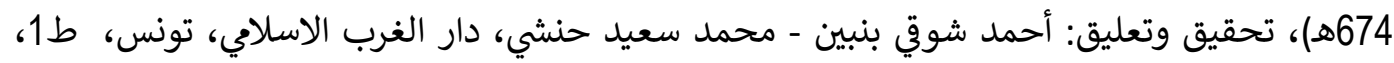
1430 هـ - 2009م. تحفيق

سر صناعة الإعراب: أبو الفتح عثمان بن جني الموصلي (المتوفى: 392ه)، دار الكتب العلمية بيروت-لبنان، ط1،

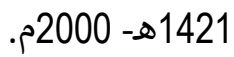

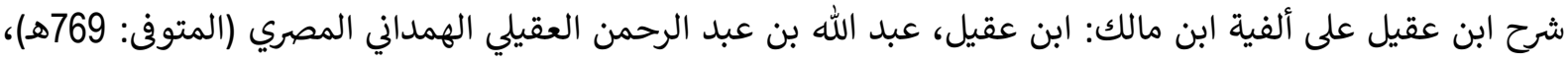

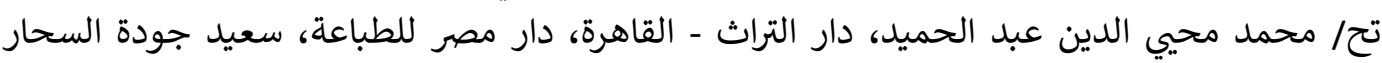

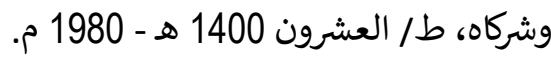
شرح الأشموني على ألفية ابن مالك: علي بن محمد بن عيسى، أبو الحسن، نور الدين الأُشْمُوني الشافعي (المتوفى:

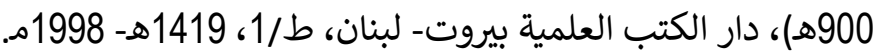

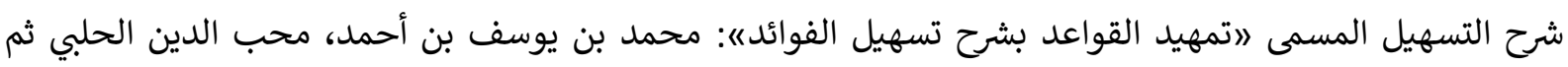

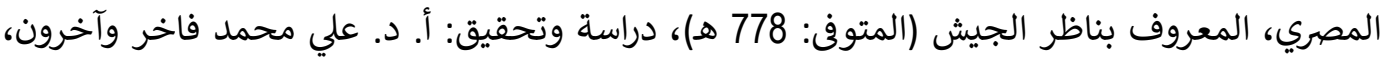

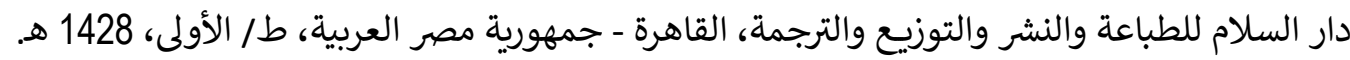

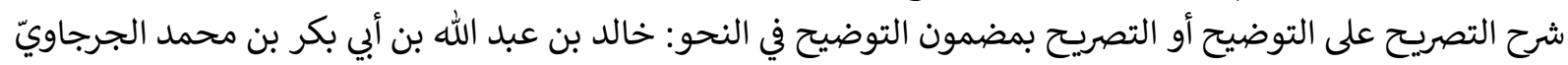

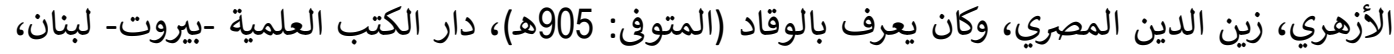

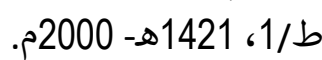

شرح الرضي على الكافية: رضي الدين الأستراباذي، طبعة جديدة مصححة ومذيلة بتعليقات مفيدة، تصحيح وتعليق:

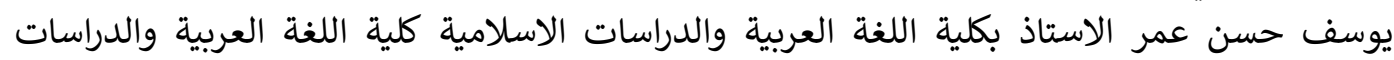

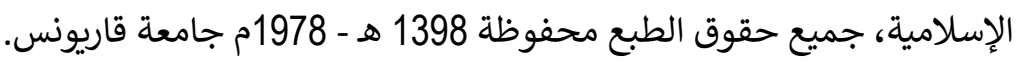

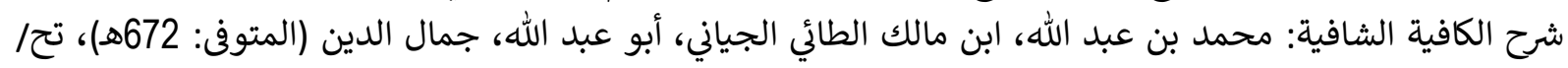

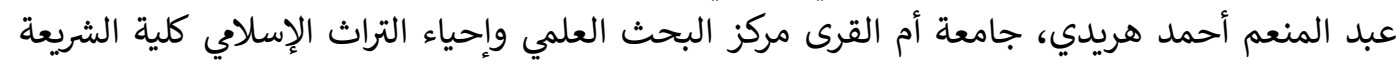

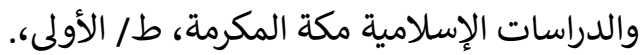

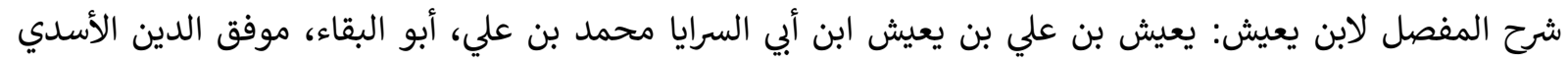

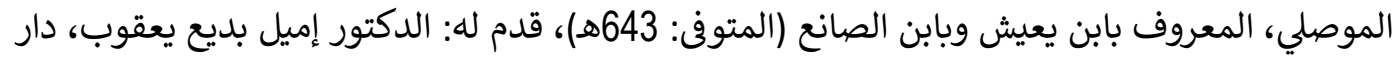

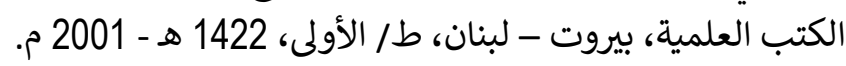

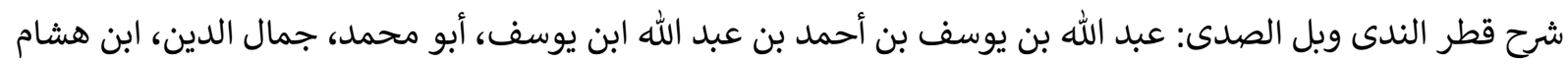

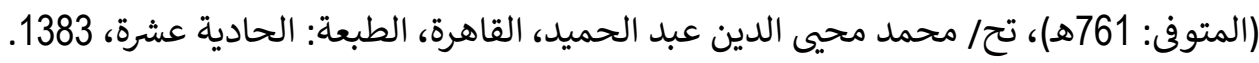




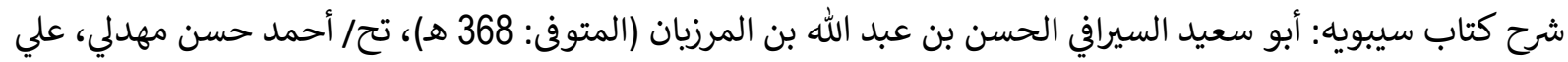

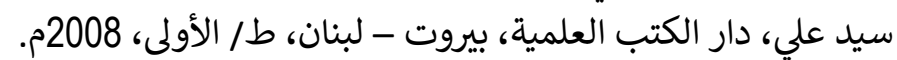

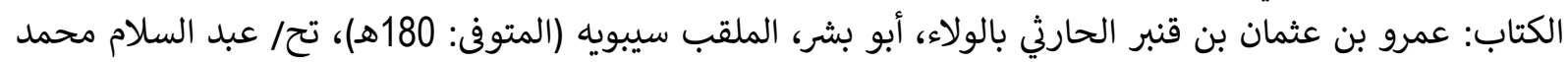

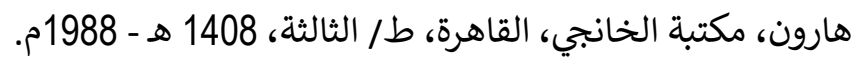

اللامات: عبد الرحمن بن إسحاق البغدادي النهاوندي الزجاجي، أبو القاسم (المتوفى: 337هـه)، تح/ مازن المبارك، دار

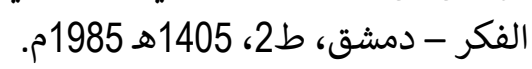

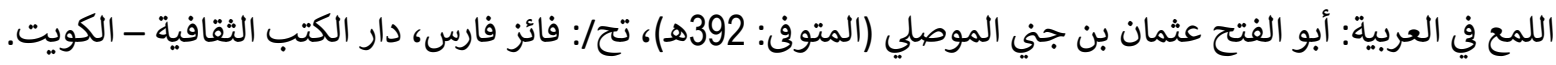

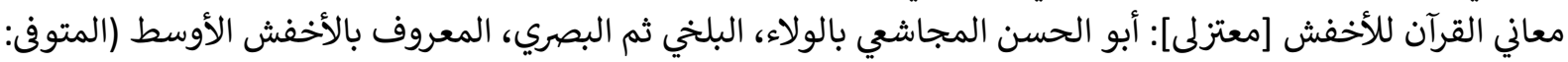

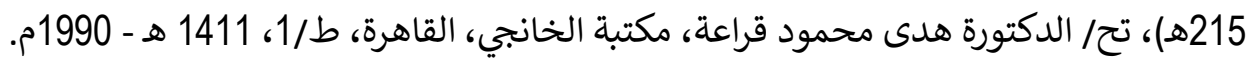

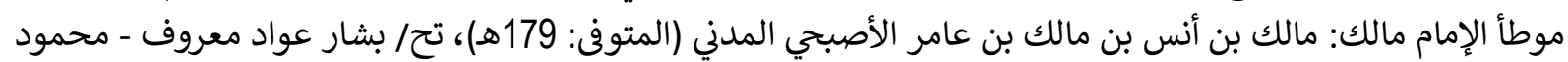

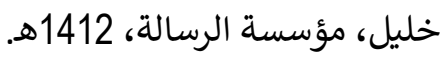

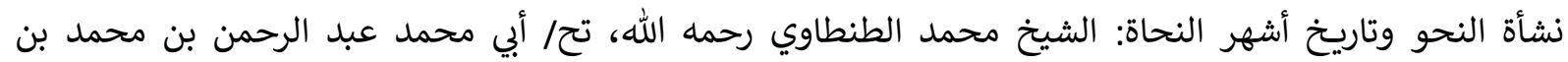

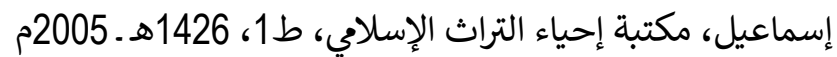

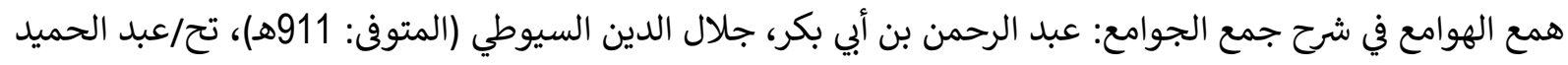
هنداوي، المكتبة التوفيقية - مصر. عيد الرحن

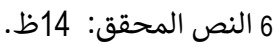
7 النص المحقق: 26 النص:

8 سورة الحشر: الآية

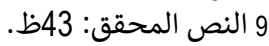

10 الكتاب لسيبويه: 86/2.

11 الاصول في النحو: 10

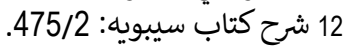

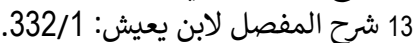

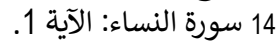

15 1 النص المحقق: 69ظة النساءة 14

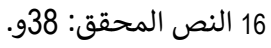

17 الكتاب لسيبويه: 56/3.

18 المقتضب: 47/2

19 المقتضب: 46/2.

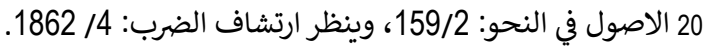

21 ينظر الكتاب لسيبويه: 56/3، المقتضب: النصو: 47/2، الاصول في النحو: 159/2.

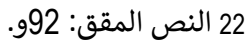

23 النص المحقق: 24 النصق: 245.

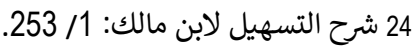

25 شرح قطر الندى وبل الندين مالصن: 24 الصدى: 112.

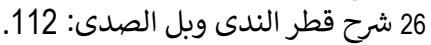

27 لم أعثر على كتابه الشافي، والقول ذالن ذكره الرضي في شرحه على الكافية: 241/3، وينظر شرح التصريح على التوضيح: 179/1.

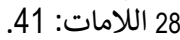

29 ينظر المصدر نفسه: 42. 
30 ارتشاف الضرب: 985/2.

31 الجنى الداني في حروف المعافي: 32 المعاني: 138.

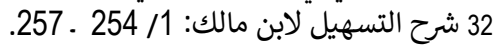
33 الكتاب: 325/3 الكرحيل

34 ينظر سر صناعة الاعراب: 15/2، العزاب: ال

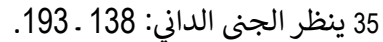
36 شرح التسهيل لابن مالك: 35 ينظر الجني الين 138/1.

37 المصدر نفسه: 38 الترحئ لابن مالك. 38 الكتاب: 38 المعدر نفهن 22

39 المصدر نفسه 372/1 الكتاب:

40 شرح التسهيل لابن مالك: 253/1 البعهي

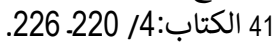

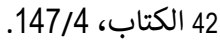

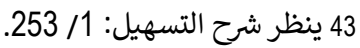

44 ينظر الجنى الداني: 43 ينظر التهي: 45 ينظر شرح الرضي: 3483/1 383، وارتشاف الضرب:

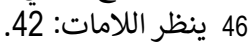
47 ينظر اللامات: 41، 4رشرح التصريح على التوضيح: 179/1، وهمع الهوامع: 306/1 ـ 307.

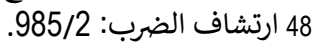

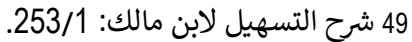
324/3 50

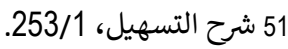

52 شرح الكافية الشافية: 51 شرحيل 53 ينظر شرح التسهيل لابن مالك: 52 الكافية: 253/1

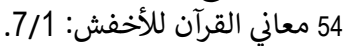

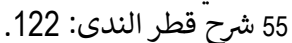

56 ينظر شرح الرضي على الكافية: 241/3، وشرح التصريح على التوضيح: 172/1.

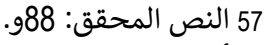
58 ألفية ابن مالك: 53 النص:

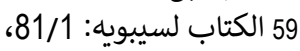

60 شرح كتاب سيبويه: 61 المقيوية:150/2.

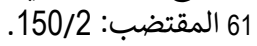

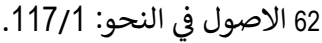
63 الايضاح العضدي: 68 الاصول النحو: 68 التورية

6464 سورة التوبة: من الآية 63 الإيذية

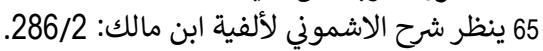

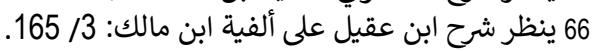

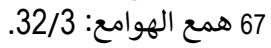

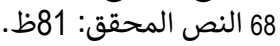
69 المقتضب: 397/4 المجنية

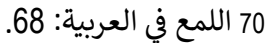
71 الكتاب: 337/2.

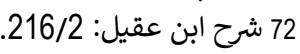
73 ينظر شرح التصريح على الإمان التوضيح: 549/1.

74 موطأ الإمام مالك: 73 ينطر النصريح على التوضيح. 75 النص المحقق: 89 النمام ماك:

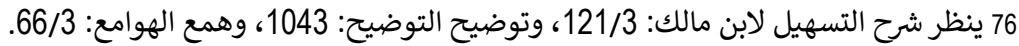

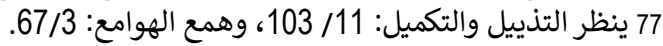

78 ينظر الاصول في النحو: 77 ينظيل 139 79 التذييل والتكميل: 111/ 103 ـ 104 ينظر الاصول 